\title{
Analysis the Determinants of Risk Factor Model for the Jordanian Banking Stocks
}

\author{
Omar Khlaif GHARAIBEH ${ }^{1}$, Ali Mustafa AL-QUDAH ${ }^{2}$
}

Received: September 10, 2020 Revised: November 02, 2020 Accepted: November 16, 2020

\begin{abstract}
The purpose of this study is to analyze the determinants of risk factor model for the Jordanian banking stocks from 2006 to 2018 . This study employs the Five-factor Fama and French's (2015) methodology and uses the annual returns of all Jordanian banks including 2 Islamic and 13 commercial banks listed on the Amman Stock Exchange (ASE) over a period of 13 years. The results show that the factors of value and profitability have an important role in evaluating the expected return in Jordanian banking stocks. Moreover, the value HML and profitability RMW factors provide the highest cumulative returns among these five factors, while the investment CMA and size SMB factors are still around zero cumulative returns. For the market factor, it provides the least negative cumulative returns. The results showed that the largest correlation is between value and investment factors which means that banks with a high book to market value become banks with a conservative investment strategy. The result of the sub-periods confirmed the value and profitability results. The findings of this study suggest that the five-factor Fama and French model is the choice of building an investment portfolio, especially the factors of value and profitability.
\end{abstract}

Keywords: Jordan, Banks, Value, Size, Investment

JEL Classification Code: G4, G32, G21

\section{Introduction}

The efficient markets hypothesis (EMH) refers to the recent stock prices which reflects all available information about the value of the company. Therefore, investors or portfolio managers cannot achieve abnormal returns or excess profits using this information. When the markets are not completely efficient, then investors choose active investment strategies to obtain a positive risk-adjusted return. To calculate abnormal returns, investors follow trading strategies that take into account returns and their risks. Schweser Notes (2015) indicate that if the average

${ }^{1}$ First Author and Corresponding Author. Associate Professor, Finance and Banking Department, Faculty of Economic and Administrative Sciences, Al-alBayt University, Jordan [Postal Address: Al-Mafraq, Jordan] Email: omar.k.gharaibeh@gmail.com

${ }^{2}$ Associate Professor, Economic Department, Faculty of Economic and Administrative Sciences, Al-alBayt University, Jordan. Alimqf@yahoo.com

(c) Copyright: The Author(s)

This is an Open Access article distributed under the terms of the Creative Commons Attribution Non-Commercial License (https://creativecommons.org/licenses/by-nc/4.0/) which permits unrestricted non-commercial use, distribution, and reproduction in any medium, provided the original work is properly cited. return is greater than expected equilibrium return, the market is ineffective and both portfolio managers and investors can achieve abnormal returns.

The CAPM model is the first model for calculating expected return introduced by Sharpe (1964). This model relies on one factor, market return and beta, to measure the sensitivity between equity and market return. The main drawback of this model is beta, which is part of the CAPM, and it is not sufficient to explain the expected return because beta cannot capture the effect of the size and value of the stocks (Fama \& French 1993). Therefore, Fama and French (1993) presented a 3-factor model by adding two additional factors, value and size, to the CAPM. Although the threefactor model provides a better explanation of expected return, it is still subject to criticism and does not explain some anomalies such as profitability and investment. These anomalies motivated Fama-French (2015) to develop a fivefactor model to explain expected return. The five-factor model is based on the following anomalies: size, value, profitability and investment in the North American market. This study stems from the fact that most of the previous studies were conducted in developed countries, and their focus has been very limited in the developing countries. This study is an extension of the analysis of the five-risk factors 
that Fama and French has conducted for North American stocks to emerging markets and applies these factors to the level of Jordanian banking stocks. Therefore, this study is a contribution to the financial literature for an understanding of the market efficiency of Jordanian bank stocks and the impact of these factors on stocks in a developing country, which deepens our knowledge of the performance of these factors on Jordanian banks listed on the Amman stock exchange (ASE). To the researcher's knowledge, this study is the first of its type to be conducted in Jordan.

Jordan is located in the heart of the Middle East. It is considered as one of the most stable countries in this region, as well as for providing a safe and attractive environment for investors. The ASE in Jordan represents a good opportunity for both local and foreign investors as it constitutes an open market and the law allows foreign investors to invest in these shares. For example, based on the ASE website in 2020, foreign investors own about $60 \%$ of the shares of Jordanian banks. Moreover, according to the ASE website, the market capitalization of Jordanian bank shares represent about 56\% from the total market capitalization value on the ASE, which is more than half. These reasons motivate the researcher to calculate the five-factor model on the stocks of Jordanian banks in the ASE.

The purpose of this paper can be summarized in three ways. Firstly, the risk factor assessment will allow to capture the size, value, profitability and investment patterns/risk factors in investment at the level of Jordanian banking stocks allowing for market deficiencies to be exploited. Secondly, to estimate the cumulative returns between these factors and which of these factors provide the highest cumulative returns. Finally, to examine the correlation between the risk factors obtained for Jordanian banking stocks. To achieve these purposes, the current study analyzed 15 Jordanian banks listed on the ASE from 2006 to 2018. Then the fivefactors were collected following the same methodology followed by Fama and French (2015).

With regard to the first purpose, the result showed that the value factor provides the highest returns followed by the factors of size and profitability. Although the second sub-period (2013-2018) for these factors is not statistically significant, they are still both economically significant and positive. In particular, the value and profitability factors yield consistent results based on the full period, as well as first and second sub-periods. This indicates that the Jordanian banking securities market may have inefficiencies and may allow active managers to beat the Amman index by selecting these factors. For the second purpose, the cumulative return result confirms the previous result documented in this paper. Value and profitability factors generate the largest cumulative returns, while market, size and investment factors producing the lowest average returns. This study also found that value and investment factors have the highest correlation and this result is consistent with Fama and French (2015) results in America. For the cumulative returns as a second objective in this study, the HML and RMW factors consistently provide the highest cumulative returns among the factors. Regarding the third objective, the highest correlation in Jordanian banks is between value and investment factors, which concluded that banks with a high ratio of book-to-market face greater difficulties in investments. For the slightest correlation, it is between size and market. The contribution of this study indicates that the value factor in Jordanian banks is still statistically significant despite the addition of profitability and investment factors and this result is inconsistent with those documented by Fama and French (2015) for North America.

\section{Literature Review}

This section introduces the methodologies, as well as theories (models) that have had a major impact on and contributed to explaining the expected returns on stocks. It starts with an analysis of the traditional stages of the birth of portfolio theory that was developed by Markowitz (1952). It then analyses the capital asset pricing model (CAPM) developed by Sharp in 1964 and Linter in 1965 and the arbitrage-pricing theory (APT) which was presented by Ross in 1976. Then the modern stages with the three-factor model was suggested by Fama and French in 1993, the fourfactor model, which was developed by Carhart in 1997 and then with the liquidity model, which was presented by Liu in 2006 and ending with the five-factor Fama and French model 2015 are all analysed. In addition, the analysis of these models revealed that each of these models has its own strengths and weaknesses as discussed below. However, the four-factor model, (which is also known as the Carhart model) provided the most accurate result with $\mathrm{R}^{2}=93 \%$ in explaining expected returns (Carhart, 1997). The Carhart model was the most applicable until Lui (2006) provided the liquidity model that captures most anomalies by using a two factors model. Fama and French (2015) have provided a five-factor model as an alternative model to the three-factor model by adding profitability and investment factors in explaining the expected returns.

\subsection{Traditional Stages}

Most previous studies concentrated on undervalued securities and did not take into consideration the effect of portfolio diversification on risk. Markowitz (1952) made a major breakthrough with his portfolio theory and he illustrated the fact that company risk could be diversified away through portfolio selection but not market risk. The contribution of his theory has been shown by the fact that the majority of the managed portfolios and pension funds around the world 
use Markowitz's theory. He developed the basic portfolio model by presenting new techniques for selecting an optimal portfolio relying on mean-variance; mean represents the expected return and variance represents the risk. Although the new technique reflected the importance of diversifying investment to decrease the total risk of a portfolio and showed how to effectively diversify, it is considered complex because he used many parameters to evaluate the expected return, variance and covariance for each of the securities. He revealed as a weakness of this theory that the variance of the rate of return was a meaningful measure of portfolio risk based on several assumptions, particularly when the investors are risk-averse and they are only concerned about the mean and variance of their one period investment return when selecting among portfolios.

Sharpe (1964) and Lintner (1965) presented CAPM as the first scientific method of defining a company price. CAPM has a strong effect on how to estimate risk and the relationship between expected return and risk. He revealed that there is a positive relationship between beta and the expected return on securities. The problem in this model is that it is based on several assumptions. Fama and French (2004) revealed that some of these assumptions were unrealistic; specifically those related to unrestricted risk free rate borrowing and lending. In addition, the assumption of unrestricted short selling appears unrealistic. Fama and French (1997) found that the CAPM is not enough to explain the expected returns and market beta does not suffice because it provides a large standard error of more than 3.0\%. Additionally, he revealed that the risk premium in the CAPM is imprecise because their result showed $5.16 \%$ the annualized average excess return on value-weight portfolio and its standard error is $2.71 \%$. Despite the theoretical failure of this model as well as its failure to capture anomalies such as size, book-tomarket and long-term past returns, till now, most financial managers in the U.S and all over the world are still using this model because it depends on one parameter (beta) and is relatively straightforward compared to any other model. On the Stock Exchange of Thailand, Pojanavatee (2020) showed that systematic risk measured by the beta coefficient did play a significantly crucial role in the prediction and formation of the rate of return. Phuoc, Kim and Su (2018) found that the robust Trimmed Square (LTS) gives more accurate estimate than the Ordinary Least Square (OLS) and daily return data provide much better estimate than monthly return data.

Ross (1976) presented a better explanation of expected stock return by using APT. This model is an alternative to the test asset-pricing model. It does not require a market portfolio and suggests restrictive assumptions such as the market is perfect, risk-averse utility maximizes and homogenous beliefs. These assumptions are the same as with CAPM, and additionally the arbitrage model assumes a linear relationship between security return and factors, the logic of arbitrage based on the investors are able to form portfolios for arbitrage by combining asset. This model is more robust than the CAPM because a market portfolio is not necessary; there are no strong assumptions on utility and no assumptions on return distributions; equilibrium returns can depend on many factors and can be easily extended into multi-period. Ross invented this model to improve the CAPM. However, the problem of this model is that it did not provide details of which economic factors affect expected returns and also it did not determine the weights of these factors based on their importance. Therefore, the main challenge of this model in securities involves the identification of risk factors. In addition, this model is more complicated than the CAPM.

The significant contribution of the study by Banz (1981) is that it provides a simple aspect of the relationship between the total market value of stocks and their returns. The strong point of this study was that he used cross sectional and time series regression. In addition, he used a methodology based on adjusted risk returns. He found that a risk adjusted return is negatively related to the firm size for at least forty years in the NYSE and that the CAPM is miss-specified. He also revealed that the relationship between the size effect and market value is not linear. Although this result is related to the size effect there is no evidence that the factor is size itself or whether size is just a proxy for one or more factors. However, the results of this study has left many unanswered questions. Furthermore, the sample of this study was exclusively taken from the NYSE and was limited by the study's size factor. Therefore, the result is not perfect.

\subsection{Modern Stages}

Fama and French (1993) three-factor model was another major breakthrough by adding two factors to the market return which are firm size and book-to-market return and this model can explain 76 percent of the expected returns plus it can capture the anomalies which caused obstacles to the CAPM. This model was developed in response to the criticism that the CAPM tended to provide imprecise forecasts of the cost of capital because it eliminated the importance of the financial risk factor. A strong point of this study is that it used a big sample including NYSE, AMEX and NASDAQ stocks. They found there is a positive relationship between expected return and book-to-market equity and that it is negatively related with the firm size. They justified the relationship because risk and return are positively related. They also proposed that size and book-to-market are proxies for distress thus the distressed companies are affected by certain business cycle factors more than companies that have less problems. Bornholt (2007) revealed that there are problems in this model. First, it still lacks a strong academic basis driven by asset pricing theory. Second, it is restricted in practice because it requires one to find the three-factor premiums and 
three-factor sensitivities. Daniel and Titman (1997) stated that the problem in this model is that it did not take into consideration all characteristics to explain expected return. Furthermore, Liu's (2006) three-factor model cannot explain all the various anomalies. Finally, they failed to calculate for the book-to-market impact that it was designed to capture. Shaharuddin, Lau, and Ahmad (2018) found that value funds yield better than the growth funds during pre-crisis period, while size factor performs better than other factors.

The important significance of Fama and French's (1997) study is that they compared the CAPM with the three-factor model to explain expected returns. They used a big sample including NYSE, AMEX and NASDAQ stocks in industry sectors from the end of July 1963 to 1994 by using two models: the CAPM and the three-factor model. They found that the three-factor model did better than the CAPM, where they found mean $\mathrm{R}^{2}=68 \%$ in the three-factor model while mean $\mathrm{R}^{2}=63 \%$ in the CAPM. In addition, the three-factor model captures anomalies which cause obstacles for the CAPM such as book-to market, size, cash flow to price and long-term past returns. However, no one can say the three-factor model is the best model, because this model is empirically produced with the help of inspiration and the three-factor model needs effective theoretical foundations. The CAPM and the three-factor model have two main problems: the first is inaccurate evaluation of risk loading and the second is inaccurate evaluation of the risk premium factor. Therefore, the researchers sought to find another model which would help them to explain the expected return better than the CAPM and the three-factor model.

The significant importance of Carhart (1997) model was that it presented a new model which is a four-factor model. This model can explain $93 \%$ of the expected return and it can capture more anomalies than the three-factor model by adding a price momentum factor. The strong point of this study was that he controlled on survivor bias by including all known equity funds from January 1962 to December 1993 in NYSE, AMEX and NASDAQ stocks. He used two models to evaluate the performance, which are the CAPM and the four-factor model. For comparative purposes he also reported the three-factor model from Fama and French (1993). He found that the four-factor model can explain the expected return better than the CAPM and three-factor models. The mean absolute errors in the four-factor model are only $0.14 \%$ per month while the mean absolute errors in the CAPM and three-factor models are $0.35 \%$ and $0.31 \%$ per month respectively. However, the problem of this model is that it is considered more complex than previous models because it has four parameters and needs more data. In other words, this model has limited usage among practitioners.

Liu (2006) revealed the importance of his study which claims that liquidity model is as accurate as Carhart model (four factor model) and even a better model because it only has two factor models. Also, this study contributes to fill the gap by clarifying the relationship between liquidity risk and all of various anomalies. Furthermore, this study presented clear evidence that liquidity risk is an important source in interpreting asset returns by using a new measure of liquidity, namely, the standardized turnover-adjusted number of zero daily trading volume over the prior 12 months. This study is different from the previous studies because it highlighted four dimensions of liquidity (price impact, trade quantity, trading cost and trading speed) with specific focus on trading speed. However, he revealed that less liquidity stocks tend to be of small value and low-turnover stocks with high bid -ask spreads and high return-to-volume ratio. Also, he revealed that high book-to-market and small firm stocks are less liquid. In fact, distressed companies are less attractive to investors. Thus, they have less liquidity. As a result, distress risk was captured by liquidity factors in a more straightforward manner than book-to-market and size proxies. However, the problem of this model is that it needs data on a daily basis.

Fama and French (2014) have shown that, on average, the value of the $\beta$ coefficient can explain $70 \%$ of the expected return on diversified portfolio, while $30 \%$ of change in expected return can be attributed to other factors related to the company's characteristics such as capitalization, its undervaluation, profitability and investment rate. Five-factor Fama and French model includes these factors.

Fama and French (2015) developed a five-factor model to solve the inability of three-factor model in explaining the expected returns. This five-factor model captures the size, value, profitability and investment patterns in stocks. They found that five-factor model can explain the expected returns better than the three-factor model. Fama and French (2015) have shown that value effect becomes redundant when using the five-factor model and including the profitability and investment factors. Using 23 developed stock markets over the period of 1992 to 2014, Cakici (2015) investigated Fama and French five-factor model in North America, Europe and Global Markets. Cakici (2015) confirmed the results of Fama and French (2015) for the U.S. stock market. However, in Japan and Asia Pacific region, the profitability and investment factors are much weaker than other markets. For the value factor, it still remains significant in all regions deposit of using the profitability and investment factors and this result is in contrast to Fama and French (2015).

Zaremba and Czapkiewicz (2017) compared four models, which are CAPM, Carhart model, three-factor model and five-factor model. They had found that the five-factor model is the best to explain portfolio returns among these models. The empirical evaluation of the five-factor model was taken by different previous studies. For example, on the Chinese equity market, Lin (2017) had shown positive result on 
using the five-factor model. At the level of Australian stock market, Chiah, Chai, Zhong, and Li (2016) pointed out the benefits of using the five-factor model to discover pricing processes, while Huynh (2018) applied the five-factor model to explain the anomalies of asset pricing.

On the Istanbul Stock Exchange, Ozkan (2018) supported the reliability of the five-factor model. For the Indonesian Stock Exchange, Paliienko, Naumenkova, and Mishchenko (2020) provided positive conclusions related to the five-factor model. Given the previous studies, there is no study that has addressed the five-risk factor on the ASE at the level of Jordanian banks. Therefore, to fill this gap, the current study investigates the use of an extended five-risk factor model for banking portfolio in Jordan over the period from 2006 until 2018.

Baylan (2020) indicated that in the literature on project risk assessment, methods for assessing and evaluating risks are only developed at the whole project level. In fact, they are not comprehensive enough to assess project risks at the activity level. Furthermore, traditional risk assessment methods such as risk matrix is not able analyse project risk quantitatively. This motivates our study to analyse the determinants of risk factors at the level of Jordanian Bank stocks listed on the ASE based on five-factor model developed by Fama and French.

\section{Data and Methodology}

\subsection{Data}

This study conducts analysis for the Jordanian banking stocks traded on the ASE at the annual level over the period of 2006 to 2018. The primary data source is the website of the ASE database. This database contains yearly stock price information such as yearly stock prices, market index returns, market capitalizations (total assets), book-to-market ratios, profit margin. The annual Treasury-bills is manually collected from Jordan Central Bank (JCB). This Treasury-bills data is used to collect excess stock return and excess market return.

Table 1 details the main summary statistics of the stock data year on year. It provides the number of Jordanian banks listed on the ASE from 2006 and 2018, average total assets, average book to market equity (BE/ME), average profit margin, and average percentage change in assets (\% Change in assets). Number of banks for stock data is 15 . The average total assets are 3,253 million dinars and the average book-toprice value is 0.95 . All data is mainly downloaded from the ASE website
Table 2 displays the number of Jordanian banks listed on the ASE from 2006 and 2018 per year, average total assets per year, average book to market equity per year (BE/ $\mathrm{ME}$ ), average annual profit margin, and average percentage change in assets per year.

\subsection{Five-Factors}

There are three methods to identify the asset pricing factors. The first approach has been introduced by Sharpe (1964), Lintner (1965) and Mossin (1966) who they provide the capital asset pricing model. This model indicates that the expected return can be computed through only one factor which is the market return. The second statistical method is motivated by Ross (1976) who introduced the arbitrage pricing theory. The third method is the threefactor model presented by Fama and French (1993). This method relies on company characteristics to generate asset pricing factors.

Table 2: Descriptive Statistics

\begin{tabular}{|l|c|c|c|c|c|}
\hline Year & $\begin{array}{c}\text { Number } \\
\text { of } \\
\text { banks }\end{array}$ & $\begin{array}{c}\text { Av. } \\
\text { Total } \\
\text { Assets }\end{array}$ & $\begin{array}{c}\text { Av. } \\
\text { BE/ } \\
\text { ME }\end{array}$ & $\begin{array}{c}\text { Av. } \\
\text { Profit } \\
\text { Margin }\end{array}$ & $\begin{array}{c}\% \\
\text { Change } \\
\text { in } \\
\text { Assets }\end{array}$ \\
\hline 2006 & 15 & 2,189 & 0.65 & 0.19 & 0.13 \\
\hline 2007 & 15 & 2,513 & 0.59 & 0.17 & 0.13 \\
\hline 2008 & 15 & 2,705 & 0.72 & 0.16 & 0.09 \\
\hline 2009 & 15 & 2,878 & 0.89 & 0.12 & 0.11 \\
\hline 2010 & 15 & 3,032 & 0.86 & 0.13 & 0.14 \\
\hline 2011 & 15 & 3,153 & 1.04 & 0.12 & 0.06 \\
\hline 2012 & 15 & 3,253 & 1.06 & 0.12 & 0.10 \\
\hline 2013 & 15 & 3,422 & 1.04 & 0.14 & 0.11 \\
\hline 2014 & 15 & 3,655 & 0.99 & 0.62 & 0.12 \\
\hline 2015 & 15 & 3,800 & 1.08 & 0.55 & 0.09 \\
\hline 2016 & 15 & 3,752 & 1.08 & 0.59 & 0.03 \\
\hline 2017 & 15 & 3,890 & 1.13 & 0.56 & 0.05 \\
\hline 2018 & 15 & 4,052 & 1.20 & 0.13 & 0.04 \\
\hline
\end{tabular}

Table 1: Average descriptive statistics

\begin{tabular}{|l|c|c|c|c|c|}
\hline & Number of Banks & Total Assets $(\mathrm{m})$ & BE/ME & Profit Margin & $\%$ Change in Assets \\
\hline Average & 15 & 3,253 & 0.95 & 0.28 & 0.09 \\
\hline
\end{tabular}


This paper follows the Fama and French's (2015) methodology using the five-factor model to compute the asset pricing model. The relationship between the characteristics of banks and the expected return motivates this study to adopt a five-factor model. The first factor in the five-factor asset pricing model is the market factor or market risk premium. This factor is calculated as the difference between the expected return in the market and the risk-free rate. This market factor is already in place at CAPM.

The second factor is the size of the bank on a small minus big (SMB) basis. This factor is calculated through the difference returns between small and big sized banks. The size of the bank depends on the total assets of the bank. This factor indicates the small effect as the smaller banks outperforms the bigger banks. Smaller banks are said to have more growth opportunities than their larger counterparts. Smaller banks also tend to have a more volatile business environment which needs to be offset by higher expected returns.

The third factor is the value on a high minus low (HML) basis. This factor is computed due to the difference in returns between value and growth stocks. Value stocks represent banks with high book-to-market ratios (value stocks), while growth stocks represent banks with low book-to-market ratios (growth stocks). This factor indicates the direct application of the risk-reward relationship. Novy-Marx (2012) indicates that the HML factor is related to the effect of leverage. It indicates that the value strategy is to buy the lower value assets by selling the surplus value assets.

Profitability is the fourth factor on a robust minus weak (RMW) basis. This factor is calculated based on the return differential between robust and weak profitable banks. According to Hou, Xue, and Zhang (2017) and Fama and French (2015) this factor is calculated by dividing earnings before interest and tax (EBIT) on the book equity. NovyMarx (2013) indicates that this strategy purchases productive assets by selling non-producing assets. This RMW factor should be positive which means that companies with greater profitability provide better results.

The fifth factor is conservative minus aggressive (Panigrahi, 2019). It is calculated as the difference in returns between companies with low and high investment strategies. Conservative banks include banks that have low investment strategies, while aggressive banks consists of banks that have high investment strategies. This paper follows the same methodology used by Fama and French (2015), and Hou, Xue, and Zhang (2015) in calculating the investment factor. They divided the annual change in total property, equipment, and plant plus the annual change in the inventories on the book value of total assets.

\subsection{Factor Calculation}

First, the market factor is calculated by the weighted market return value minus the risk-free rate based on the annual data.
For the account of SMB, 3 portfolios are established with all Jordanian banks listed on the ASE, which represent more than $50 \%$ of the market capitalization of ASE. Each portfolio is created annually. Every year, the stocks of Jordanian banks are sorted into three portfolios according to their size (total assets). The first portfolio includes the bank stocks which account for $30 \%$ of the highest total assets. The second portfolio is medium bank stocks which account for $40 \%$ of total average assets. The third portfolio consists of the remaining banks, which together accounts for the remaining $30 \%$ of the lowest total asset. Going forward like this, the stocks of Jordanian banks are divided into three groups of stocks of three different sizes.

To calculate the HML factor, 3 portfolios are created based on the highest price to book value ratio of $30 \%$ representing growth stocks, the $40 \%$ medium and the lowest price to book value ratio of $30 \%$ representing stock value. These break points relatively follow Fama and French (1993).

The bank stocks with a higher price to book value ratio of $30 \%$ are classified as growth stocks, while those within 70 and $100 \%$ are classified as value stocks. Intermediate stocks are those whose price to book value ranges from 30 to 70 percent. As a result, 3 portfolios are indicated by $\mathrm{H}, \mathrm{M}$, and $\mathrm{L}$ (with $\mathrm{H}, \mathrm{M}$ and $\mathrm{L}$ denoting high, medium and low values, respectively). This paper utilized data from two extreme portfolios, high minus low HML.

The RMW factor is calculated in the same way as HML. The only difference is that RMW is based on the breakpoints operating profit margin rather than price to book value. Robust banks indicate higher operating profits, weak banks indicate lower operating profit margin. $3 \mathrm{R}, \mathrm{M}$ and $\mathrm{W}$ portfolios are sorted (with R, M, and W denoting robust, medium and weak banks, respectively). The final RMW factor is averaging returns for robust minus weak operating profits.

The CMA factor is calculated the same way for HML and RML but the only difference is that the CMA is calculated due to the previous year's investment. The lower the increase in assets, the more conservative the stocks are, while the higher the increase in assets, the more aggressive stocks. 3 conservative $\mathrm{C}, \mathrm{M}$ and $\mathrm{A}$ are constructed. Then the Conservative minus aggressive CMA is calculated on the basis of the average CMA.

\section{Results}

Table 3 shows in detail the average, standard deviations and $t$-values of the risk factor models computed for Jordanian banks in the first column. The second column indicates the market return for MSCI in Jordan. 15 Jordanian banks are categorized into 3 portfolios based on 30\% (Top), 40\% (Medium), and $30 \%$ (Bottom) for size $\mathrm{S}$ and $\mathrm{B}$ represent small minus big factor $\mathrm{SMB}$, the value $(\mathrm{H}$ and $\mathrm{L}$ means high minus low value factor $\mathrm{HML}$ ), profitability (R and $\mathrm{W}$ stands for robust minus weak operating profit margin factor RMW) and investment ( $\mathrm{C}$ and $\mathrm{A}$ stands conservative minus aggressive factor $\mathrm{CMA}$ ). 
Table 3: Descriptive statistics for risk factors: $2006-2018$

\begin{tabular}{|c|c|c|c|c|c|c|c|}
\hline & \multirow{2}{*}{$\begin{array}{c}\text { Market } \\
\text { Effect }\end{array}$} & \multicolumn{3}{|c|}{ Size Effect } & \multicolumn{3}{|c|}{ Value Effect } \\
\hline & & $S$ & $B$ & SMB & $\mathrm{H}$ & L & HML \\
\hline Av. & -5.09 & -6.67 & -7.05 & -6.86 & -2.95 & -9.24 & -6.09 \\
\hline S.D. & 13.40 & 14.11 & 18.08 & 11.42 & 15.10 & 12.41 & 10.58 \\
\hline \multirow[t]{3}{*}{$t$-stat } & $(-1.37)$ & $(-1.7)$ & $(-1.41)$ & $(-2.17)$ & $(-0.7)$ & $(-2.68)$ & $(-2.08)$ \\
\hline & \multicolumn{4}{|c|}{ Operating Profitability Effect } & \multicolumn{3}{|c|}{ Investment Effect } \\
\hline & \multicolumn{2}{|l|}{$\mathrm{R}$} & W & RMW & C & A & CMA \\
\hline Av. & \multicolumn{2}{|l|}{-4.57} & -9.80 & -7.19 & -7.72 & -7.09 & -7.40 \\
\hline S.D. & \multicolumn{2}{|l|}{18.79} & 15.64 & 9.42 & 14.41 & 14.31 & 8.70 \\
\hline$t$-stat & \multicolumn{2}{|l|}{$(-0.88)$} & $(-2.26)$ & $(-2.75)$ & $(-1.93)$ & $(-1.79)$ & $(-3.07)$ \\
\hline
\end{tabular}

Table 3 shows that during the period 2006-2018, the overall average return of the Jordanian banking securities market had a negative trend. However, average returns on stocks of small size, high value, robust operating profitability and aggressive investment tend to outperform stocks of big size, low value, weak operating profitability and conservative investment. For example, the average return on stocks with small size, high value, robust operating profitability and aggressive investment provides $-6.67 \%$, $-2.95 \%,-4.57 \%$ and $-7.09 \%$ while the average return on stocks with big size, low value, weak operating profitability and conservative investment earn $-7.05 \%,-9.24 \%,-9.80 \%$ and $-7.72 \%$, respectively. Table 3 indicates that although the market factor is not statistically significant, it provides the highest return. Nevertheless, the average returns of Jordanian bank stocks are statistically significant for all the four factors SMB, HML, RMW, and CMA. In particular, evidence indicates that the value factor yields the largest statistically significant return for the portfolio and is followed by the size, profitability and investment factors in that order. This is an evidence of small size, high value, robust operating profitability and aggressive investment impacts.

The main conclusion that can be drawn from Table 3 is that all factors have a negative sign that concludes that the performance of both Jordanian banks and the ASE is in continuous decline. In general, all the four factors lead to minimizing losses and have a contribution to average return which only means that stock with low value, small, profitable and banks with aggressive investment strategies provide greater returns than the stocks that have growth, big, unprofitable and conservative investment counterparts. Additionally, all four factors provide a statistically significant return. However, for the investment factor, aggressive investment is much higher than conservative investment in the Jordanian banks. This finding contradicts Fama and French (2015) and indicates that the value stock tends to be a conservative stocks and this fact may be due to greater inefficiency at the ASE. In addition, the value factor is still significant despite the use of profitability and investment factors. Although this result is inconsistent with that of Fama and French (2015), this result is in line with that of Cakici (2015) who found a similar result when using a five-factor model in 23 developed stock markets.

Figure 1 shows the cumulative returns of these five factors. Looking at Figure 1, it is clear that HML and RMW factors provide the highest cumulative returns. On the other hand, SMB and CMA factors remain within the limits of zero cumulative returns. The market factor provides negative cumulative returns, which means that not only do these four factors outperform the market factor, but these banks also outperform the MSCI market index.

The next section divides the sample into two periods to test the robustness of the results achieved in the previous section. The first sub-period extends from 2006 to 2012 and this first sub-period includes the financial crisis (2008), while the second sub-period ranges from 2013 to 2018 which is a more stable sub-period. The risk factors for both periods are recalculated in the same way as in the previous section.

Table 4 shows the average, standard deviations and $t$-values of the risk factor models computed for Jordanian banks in the first column. The portfolios are sorted on the same manner in Table 3, with 15 Jordanian banks ranked in 3 portfolios based on 30\% (Top), 40\% (Medium), and 30\% (Bottom) for size $\mathrm{S}$ and $\mathrm{B}$ means small minus big factor $\mathrm{SMB}$, the value $\mathrm{H}$ and $\mathrm{L}$ means high minus low value factor HML, the profitability $\mathrm{R}$ and $\mathrm{W}$ means robust minus weak operating profit margin RMW factor and the investment $\mathrm{C}$ and A means conservative minus aggressive factor CMA. 


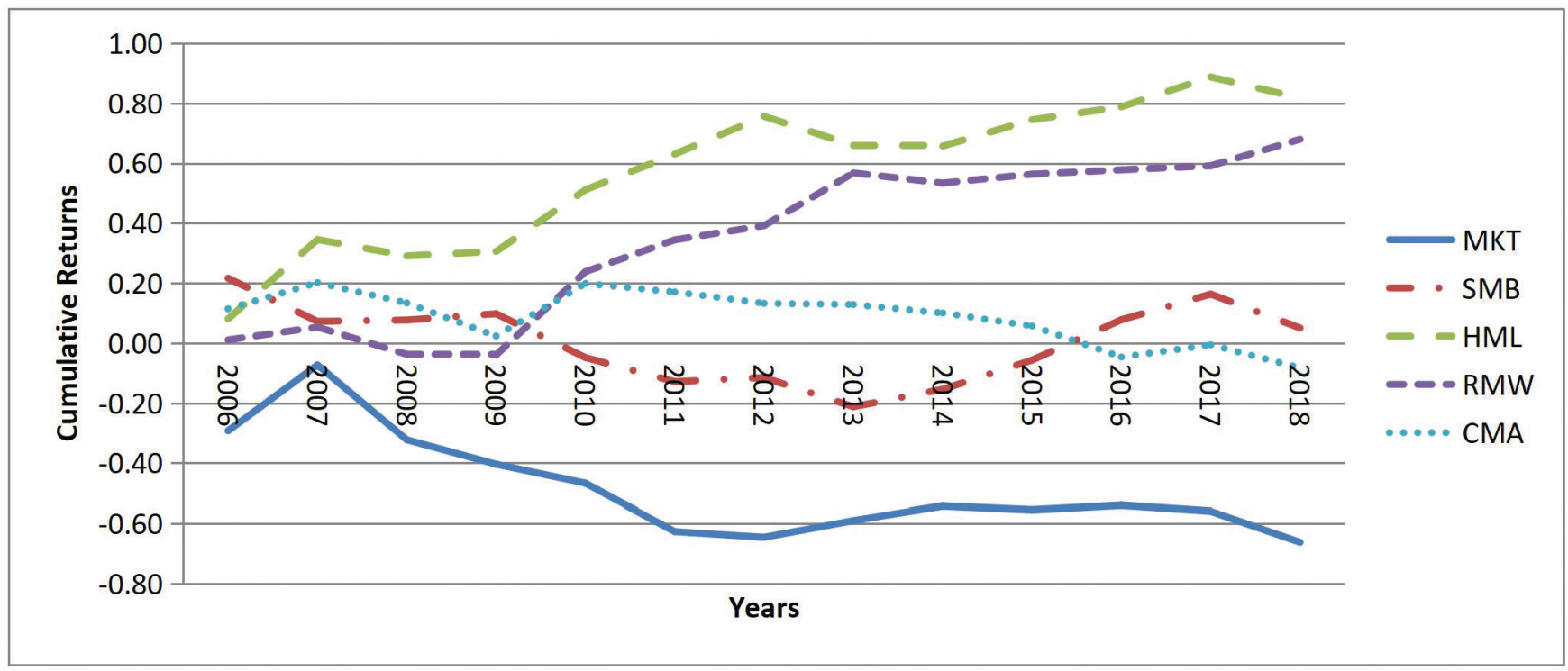

Figure 1: Cumulative Returns of Strategies in the Full Period

Table 4: Descriptive statistics for risk factors for two different periods- 2006 to 2012 (Panel A) and 2013 to 2018 (Panel B)

\begin{tabular}{|c|c|c|c|c|c|c|c|}
\hline \multicolumn{8}{|c|}{ Panel A:2006-2012 } \\
\hline & Market & \multicolumn{3}{|c|}{ Size Effect } & \multicolumn{3}{|c|}{ Value Effect } \\
\hline & Effect & $\mathbf{S}$ & B & SMB & $\mathbf{H}$ & $\mathbf{L}$ & HML \\
\hline Av. & -9.22 & -13.75 & -12.11 & -12.93 & -5.45 & -16.25 & -10.85 \\
\hline S.D. & 16.97 & 13.77 & 23.16 & 12.52 & 20.47 & 11.62 & 10.83 \\
\hline \multirow[t]{3}{*}{ t-stat } & $(-1.44)$ & $(-2.64)$ & $(-1.38)$ & $(-2.73)$ & $(-0.70)$ & $(-3.70)$ & $(-2.65)$ \\
\hline & \multicolumn{4}{|c|}{ Operating Profitability Effect } & \multicolumn{3}{|c|}{ Investment Effect } \\
\hline & $\mathbf{R}$ & $\mathbf{W}$ & & RMW & C & A & CMA \\
\hline Av. & -10.10 & -15.7 & & -12.90 & -12.27 & -14.17 & -13.22 \\
\hline S.D. & 23.43 & 18.4 & & 11.48 & 18.00 & 15.57 & 10.64 \\
\hline t-stat & $(-1.14)$ & $(-2.2$ & & $(-2.97)$ & $(-1.80)$ & $(-2.41)$ & $(-3.29)$ \\
\hline \multicolumn{8}{|c|}{ Panel B: 2013-2018 } \\
\hline & Market & \multicolumn{3}{|c|}{ Size Effect } & \multicolumn{3}{|c|}{ Value Effect } \\
\hline & Effect & $\mathbf{S}$ & B & SMB & $\mathbf{H}$ & $\mathbf{L}$ & HML \\
\hline Av. & -0.51 & 0.69 & -1.87 & -0.59 & 0.51 & -2.17 & -0.83 \\
\hline S.D. & 5.31 & 9.35 & 7.52 & 9.67 & 4.87 & 7.58 & 8.63 \\
\hline \multirow[t]{3}{*}{ t-stat } & $(-0.25)$ & $(0.20)$ & $(-0.66)$ & $(-0.16)$ & $(0.27)$ & $(-0.76)$ & $(-0.26)$ \\
\hline & \multicolumn{4}{|c|}{ Operating Profitability Effect } & \multicolumn{3}{|c|}{ Investment Effect } \\
\hline & $\mathbf{R}$ & $\mathbf{W}$ & & RMW & C & A & CMA \\
\hline Av. & 1.54 & -3.2 & & -0.86 & -2.88 & 0.74 & -1.07 \\
\hline S.D. & 8.96 & 7.90 & & 6.75 & 6.35 & 6.48 & 4.70 \\
\hline t-stat & $(0.45)$ & $(-1.0$ & & $(-0.34)$ & $(-1.20)$ & $(0.30)$ & $(-0.60)$ \\
\hline
\end{tabular}


Table 4 in Panel A confirms previous results in Table 3 that factors of value and profitability are statistically significant. However, the stocks of big Jordanian banks outperformed the smaller banks in the first sub-period in Panel A, which means that in that period the stocks of big banks provide a higher average return than the stocks of smaller banks. On the other hand, for Panel B, all these four factors are statistically insignificant and different from the previous first period in Panel A. However, although all of these four risk factors in the second sub-period (Panel B) have low $t$-statistics, they provide average positive return along with the small size $\mathrm{S}$, high value $\mathrm{H}$, robust operating profitability $\mathrm{R}$ and aggressive investment $\mathrm{A}$. For example, the average return on stocks with small size, high value, robust operating profitability and aggressive investment were $0.69 \%, 0.51 \%, 1.54 \%$ and $1.74 \%$, respectively. This late finding give investors an opportunity to make a bit of profit.

In general, given Table 3 and 4, high-value $H$ and robust profitability $\mathrm{R}$ consistently provide an average greater than low-value $\mathrm{L}$ and weak profitability $\mathrm{W}$. The first sub-period spanning from 2006 to 2012 has a negative sign. This can be attributed to global financial crisis and the reversal of the recession, in addition to the fact that this period was not politically stable due to the events of the Arab Spring, while the second sub-period extending from 2013 to 2018 provide a positive sign compared to the first sub-period.

Figure 2 shows the cumulative returns of these five factors in the first sub-period from 2006 to 2012. The performance of these five factors is relatively close to zero over the period from 2006 to 2009. This lower cumulative return during this period can be attributed to the global financial crises. However, at the beginning of 2010, HML and RMW factors started to rise and achieve the highest cumulative returns, while CMA and SMB were still around zero cumulative returns. In general, market factor returns have declined rapidly towards negative cumulative returns.

Figure 3 shows the cumulative returns for five factors in the second sub-period from 2013 to 2018. In general, Figure 3 confirms previous results in terms of HML and RMW still providing the highest cumulative returns, while CMA and SMB are still around zero cumulative returns. Finally, the market factor continues to decline and provides negative cumulative returns. Figure 2 and 3 confirm the result shown in Figure 1 and indicate that the performance of Jordanian banking stocks outperforms the performance the market, as well as investing in value and profitability stocks provides large cumulative returns.

For Jordanian bank's portfolio, the biggest correlation is between HML value and strategy CMA investment strategy. This finding supports the general belief that banks with a higher book to market value become banks with a conservative investment strategy. Most value banks have low stock prices because of financial distress. Therefore, it is difficult for these banks to follow aggressive strategies. This result is consistent with that of the U.S. in Fama and French (2015). The correlation between HML value and RMW profitability is positive but weak. This result indicates that banks with a high book to market value tend to be relatively profitable banks. This means that most of the investors prefer to buy a relatively lower market rate of the banks because they believe that investing in banks with higher book to market value will yield high profits in the future. Therefore, stock of value tend to be profit oriented.

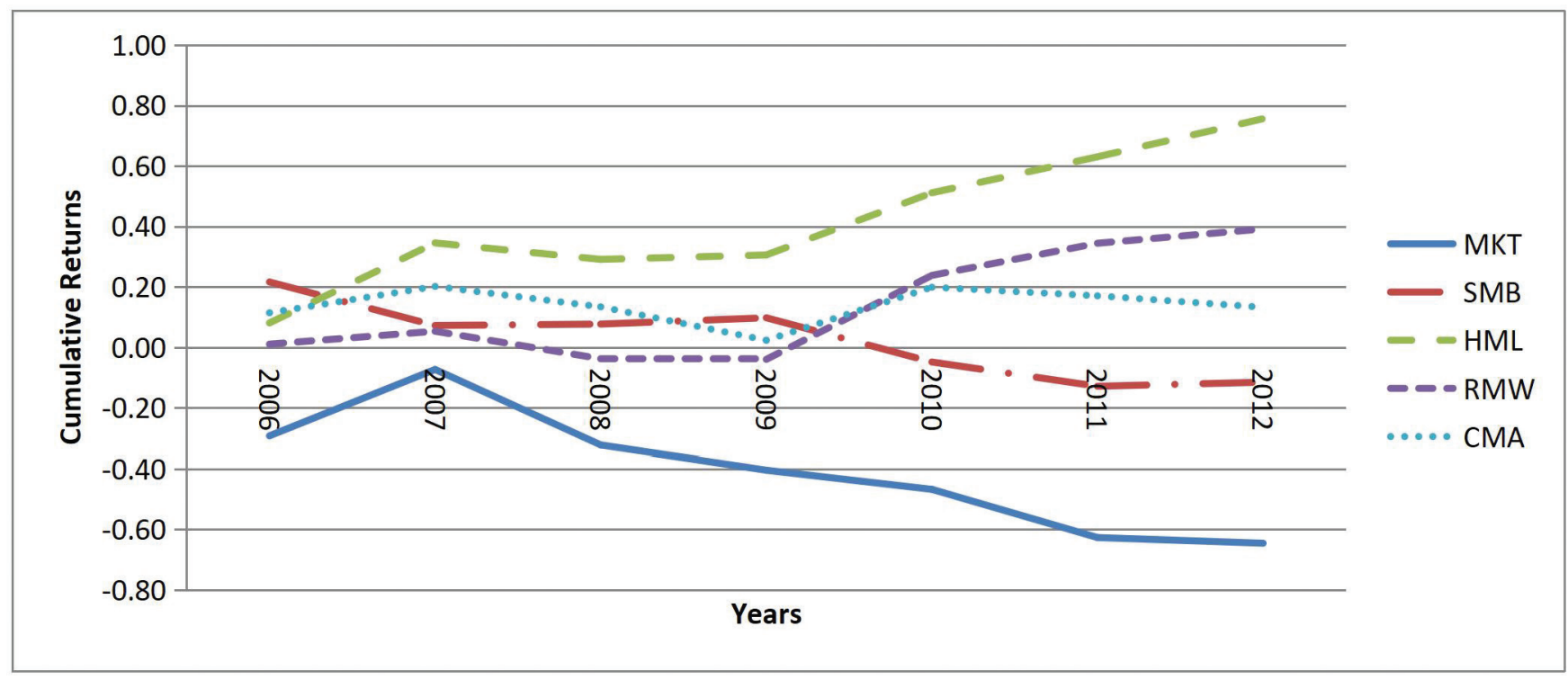

Figure 2: Cumulative Returns of Strategies in the First Sub-period 


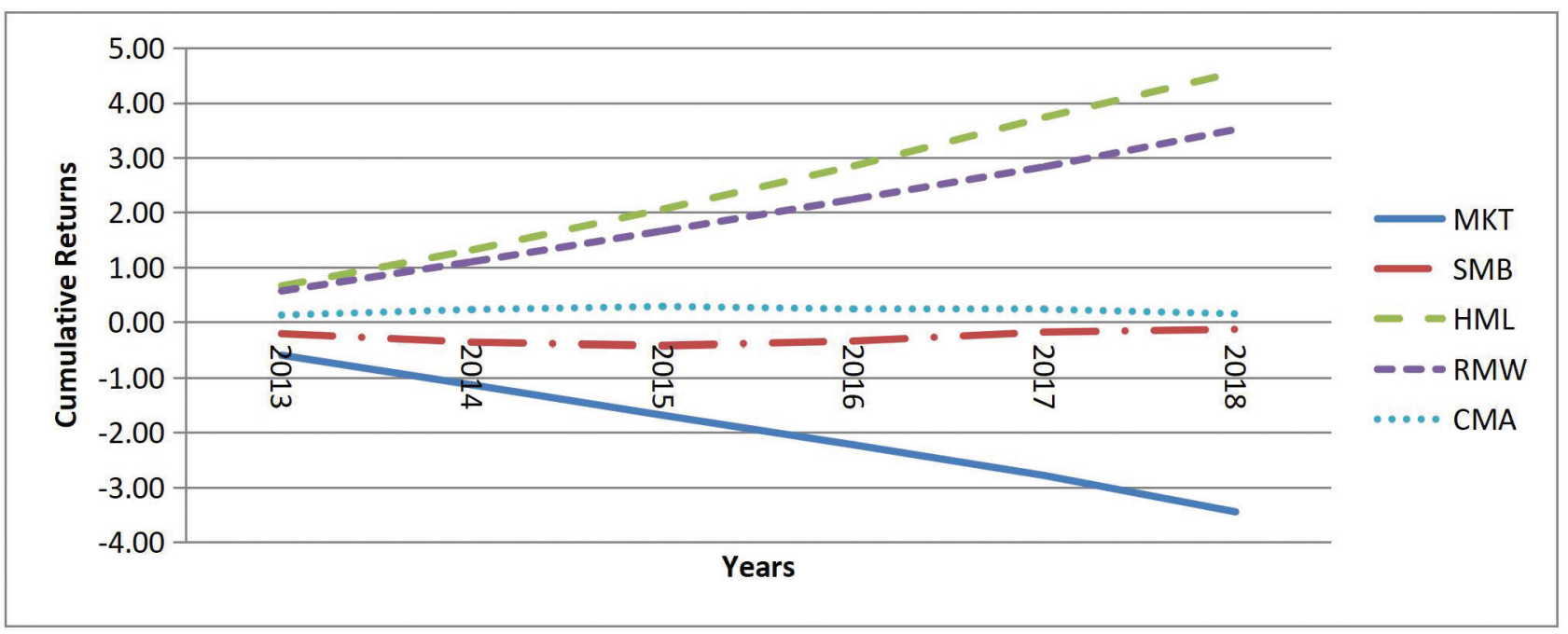

Figure 3: Cumulative Returns of Strategies in the Second Sub-period

Table 5: Correlations between the five factors in Jordanian banks

\begin{tabular}{|l|c|c|c|c|c|}
\hline & MKT & SMB & HML & RMW & CMA \\
\hline MKT & $100 \%$ & & & & \\
\hline SMB & $-36 \%$ & $100 \%$ & & & \\
\hline HML & $31 \%$ & $-15 \%$ & $100 \%$ & & \\
\hline RMW & $18 \%$ & $-61 \%$ & $26 \%$ & $100 \%$ & \\
\hline CMA & $4 \%$ & $-18 \%$ & $62 \%$ & $52 \%$ & $100 \%$ \\
\hline
\end{tabular}

However, this finding is inconsistent with that of Fama and French (2015) who found the correlation between value and profitability to be negative. They explain this negative correlation that investors prefer to pay a higher market price for profitable companies than they would for non-profit companies. The correlation between RMW profitability and CMW investment is positive but weak, which means that the more profitable banks tend to be relatively more conservative when making investments.

An interesting conclusion can be drawn from the correlations of size factor SMB with all factors being negative. This finding might come as a surprise given that smaller stocks generally provide higher average returns than the bigger stocks. That is why the big Jordanian bank size in Table 4 for the first sub-period outperforms the small size. This can be attributed to investors' tendency towards large-sized banks in Jordan during the 2008 global financial crises and the Arabic Spring because they believed that large banks in Jordan were safer than the smaller ones. Market factor correlation is $-36 \%$ with size factor, while market factor correlation is relatively insignificant of $31 \%$,
$18 \%$, and $4 \%$ with value, profitability and investment factor, respectively.

\section{Conclusions}

The purpose of this study is to compute the five risk factor model using Fama and French's (2015) methodology. The annual returns of 15 Jordanian banks listed on the ASE were used over the period of 13 years (2006-2018). The main result of the current study was that all factors have a negative sign, which concluded that the performance of ASE is in a continuous decline during the study period. This can be attributed to the economic and political conditions that the region has experienced in the past decade. the factors of SMB size, HML value, RMW profitability are statistically significant and differ from zero at the full period level. These risk factors are similar to those documented by Fama and French (2015) and follow the same trend.

The factor of value HML provides a greater contribution to the average return between these factors, while Fama and French (2015) found that the market factor produces a greater contribution. This finding supports the idea already examined, that buying stocks that tend to have high bookto-market (cheap) and selling stocks that tend to have low book-to-market (expensive) should be a sound strategy. The size factor is consistent with the results of Fama and French (2015), where smaller banks offer better returns than the larger banks. This confirms the idea that small banks risk cash reserve (liquidity) and reach the lowest level. Therefore, this is reflected in the cost of financing when small banks need liquidity. Profitability factor has a positively significant effect on returns on Jordanian banking stocks. This indicates that managers have the efficiency in managing the assets of 
these Jordanian banks. The greater the efficiency of asset management, the greater the stock returns.

However, when dividing the sample into two sub-periods and examining each of this new sample independently, the results of the value and profitability factors are confirmed, while the size and investment factors change dramatically. However, after dividing the sample into two periods, in the first sub-period extending from 2006 to 2012, the large Jordanian banks achieved better returns than those of small Jordanian banks, while the second sub-period, ranging from 2013 to 2018, the small Jordanian banks outperform the large Jordanian banks. The first sub-period includes data on the 2008 global financial crisis and the Arabic Spring. These economic and political events distorted the behavior of the ASE in Jordan at the level of banks and forced investors to move towards the large Jordanian banks, believing that they are safer than the small Jordanian banks.

In terms of cumulative return results, the factors of value and profitability consistently provide the highest cumulative return. In contrast, size and investment factors provide a cumulative return close to zero. However, the cumulative return provided by the market factor is negative which means that the performance of these factors at the level of Jordanian bank stocks outperforms the market.

The greatest correlation between value and investment risk factors. This result is consistent with those of Fama and French (2015) in terms of direction. However, the aggressive investment side (A) is consistently greater than the conservative investment side (C) in the current study which is in contrast to the Fama and French study (2015) who found that the conservative investment side $(\mathrm{C})$ is outperforming the aggressive investment side (A). With the general interpretation that banks with high book to market value become banks with a conservative investment strategy. The correlation between RMW profitability and CMW investment is positive but weak, which means that more profitable banks tend to be more conservative when investing. Jordan differs from the rest of the world in that it is located in a politically unstable region. In addition, most of the depositors in Jordanian banks are commercial, industrial and service companies, and this type of depositors cannot predict the dates for withdrawing their money, which drives the banks to maintain high liquidity and follow a cautious lending policy, which means that the bank is directed to conservative investment. Finally, the factors of value and profitability also show a positive correlation in signaling but they are still weak. This means that the book value of Jordanian banks is large compared to the market value. This is an indication of a decline in the financial performance of banks in general, and thus it negatively affects the stock prices in the ASE. Actually, by reviewing the performance of banks during the study period, the average return on assets does not exceed $1 \%$. Finally, one of the lowest correlations between value and size has been documented.
The value factor clearly adds more information and helps to calculate returns more than the other four factors. However, when building an investor to build an investment portfolio on the basis of size, value, profitability and investment, the five-factor model is a choice. A further study can be conducted to determine the role of these five factors in the rest of the sectors in the ASE, as well as in another emerging financial market, to compare these results with the results in the developed markets.

\section{References}

Baylan, E. B. (2020). A Novel Project Risk Assessment Method Development via AHP-TOPSIS Hybrid Algorithm. Emerging Science Journal, 4(5), 390-410. https://www.ijournalse.org/ index.php/ESJ/article/view/410

Banz, R. W. (1981). The relationship between return and market value of common stocks. Journal of Financial Economics, 9(1), 3-18. https://doi.org/10.1016/0304405X(81)90018-0.

Bornholt, G. (2007). Extending the capital asset pricing model: the reward beta approach. Accounting \& Finance, 47(1), 69-83. https://doi.org/10.1111/j.1467-629X.2007.00202.x.

Cakici, N. (2015). The five-factor Fama-French model: International evidence. Available at SSRN 2601662. https://papers.ssrn.com/ sol3/papers.cfm?abstract_id=2601662.

Carhart, M. M. (1997). On persistence in mutual fund performance. Journal of Finance, 52(1), 57-82. https://doi. org/10.1111/j.1540-6261.1997.tb03808.x.

Chiah, M., Chai, D., Zhong, A., \& Li, S. (2016). A Better Model? An empirical investigation of the Fama-French five-factor model in Australia. International Review of Finance, 16(4), 595-638. https://doi.org/10.1111/irfi.12099.

Daniel, K., \& Titman, S. (1997). Evidence on the characteristics of cross sectional variations in stock returns. The Journal of Finance, 52(1), 1-33. https://doi.org/10.1111/j.1540-6261.1997. tb03806.x.

Fama, E., \& French, K. (2014). A five-factor asset pricing model, fama-miller working paper: September. https://doi. org/10.1016/j.jfineco.2014.10.010.

Fama, E. F., \& French, K. R. (1993). Common risk factors in the returns on stocks and bonds. Journal of Financial Economics, 33(1), 3-56. https://doi.org/10.1016/0304-405X(93)90023-5.

Fama, E. F., \& French, K. R. (1997). Industry costs of equity. Journal of Financial Economics, 43(2), 153-193. https://doi. org/10.1016/S0304-405X(96)00896-3.

Fama, E. F., \& French, K. R. (2004). The capital asset pricing model: theory and evidence. Journal of Economic Perspectives, 18(3), 25-46. DOI: $10.1257 / 0895330042162430$.

Fama, E. F., \& French, K. R. (2015). A five-factor asset pricing model. Journal of Financial Economics, 116(1), 1-22. https:// doi.org/10.1016/j.jfineco.2014.10.010. 
Hou, K., Xue, C., \& Zhang, L. (2015). Digesting anomalies: An investment approach. The Review of Financial Studies, 28(3), 650-705. https://doi.org/10.1093/rfs/hhu068.

Hou, K., Xue, C., \& Zhang, L. (2017). A comparison of new factor models. Fisher College of Business Working Paper (2015-03), 05. https://econpapers.repec.org/paper/eclohidic/2015-05.htm.

Huynh, T. D. (2018). Explaining anomalies in Australia with a fivefactor asset pricing model. International Review of Finance, 18(1), 123-135. https://doi.org/10.1111/irfi.12125

Lin, Q. (2017). Noisy prices and the Fama-French five-factor asset pricing model in China. Emerging Markets Review, 31, 141163. https://doi.org/10.1016/j.ememar.2017.04.002.

Lintner, J. (1965). The valuation of risk assets and the selection of risky investments in stock portfolios and capital budgets. The Review of Economics and Statistics, 47(1), 13-37. https://doi. org/10.1016/B978-0-12-780850-5.50018-6.

Liu, W. (2006). A liquidity-augmented capital asset pricing model. Journal of Financial Economics, 82(3), 631-671. https://doi. org/10.1016/j.jfineco.2005.10.001.

Markowitz, H. (1952). Portfolio selection. Journal of Finance, 7(1), 77-91. https://www.math.ust.hk/ maykwok/courses/ma362/ 07F/markowitz_JF.pdf

Mossin, J. (1966). Equilibrium in a capital asset market. Econometrica: Journal of the Econometric Society, 768-783. https://www.jstor.org/stable/1910098.

Novy-Marx, R. (2012). Is momentum really momentum? Journal of Financial Economics, 103(3), 429-453. https://doi. org/10.1016/j.jfineco.2011.05.003.

Novy-Marx, R. (2013). The other side of value: The gross profitability premium. Journal of Financial Economics, 108(1), 1-28. https://doi.org/10.1016/j.jfineco.2013.01.003.

Ozkan, N. (2018). Fama-French Five Factir Model and The Necessity oF Value Factor: Evidence from Istanbul Stock Exchange. Procedia, 8(1), 14-17. https://doi.org/10.17261/ Pressacademia.2018.972
Paliienko, O., Naumenkova, S., \& Mishchenko, S. (2020). An empirical investigation of the Fama-French five-factor model. Investment Management \& Financial Innovations, 17(1), 143. http://dx.doi.org/10.21511/imfi.17(1).2020.13.

Panigrahi, C. (2019). Validity of Altman's 'Z'Score Model in Predicting Financial Distress of Pharmaceutical Companies. NMIMS Journal of Economics and Public Policy, 4(1). https:// papers.ssrn.com/sol3/papers.cfm?abstract_id=3326312.

Phuoc, L. T., Kim, K. S., \& Su, Y. (2018). Reexamination of Estimating Beta Coecient as a Risk Measure in CAPM. Journal of Asian Finance, Economics, and Business, 5(1), 11-16. https:// doi.org/10.13106/jafeb.2018.vol5.no1.11

Pojanavatee, S. (2020). Tests of a Four-Factor Asset Pricing Model: The Stock Exchange of Thailand. Journal of Asian Finance, Economics, and Business, 7(9), 117-123. https://doi. org/10.13106/jafeb.2020.vol7.no9.117

Ross, S. A. (1976). The arbitrage theory of capital asset pricing. Journal of Economic Theory, 13(3), 341-360. https://doi.org/10 .1142/9789814417358_0001.

Schweser Notes for the CFA. (2015). Kaplan. https://www. amazon.com/Kaplan-Schweser-Package-Quicksheet-Practice/ $\mathrm{dp} / 1475427638$

Shaharuddin, S. S., Lau, W. Y., \& Ahmad, R. (2018). Is the Fama french three-factor model relevant? Evidence from Islamic unit trust funds. Journal of Asian Finance, Economics and Business, 5(4), 21-34. http://doi.org/10.13106/jafeb.2018. vol5.no4.21.

Sharpe, W. F. (1964). Capital asset prices: A theory of market equilibrium under conditions of risk. Journal of Finance, 19(3), 425-442. https://doi.org/10.1111/j.1540-6261.1964. tb02865.x.

Zaremba, A., \& Czapkiewicz, A. (2017). Digesting anomalies in emerging European markets: A comparison of factor pricing models. Emerging Markets Review, 31, 1-15. https://doi. org/10.1016/j.ememar.2016.12.002. 